\title{
Catheter Ablation of Mitral Isthmus Flutter Post Mitral Valve Repair and Surgical Maze: Case Report and Review of the Literature
}

\author{
Sergio Conti ${ }^{1,2}$, Zaev Wulffhart ${ }^{1,2}$ \\ ${ }^{1}$ Southlake Regional Health Centre, Newmarket, Canada \\ ${ }^{2}$ University of Toronto, Toronto, Canada \\ Email: sergioconti.md@gmail.com
}

How to cite this paper: Conti, S. and Wulffhart, Z. (2017) Catheter Ablation of Mitral Isthmus Flutter Post Mitral Valve Repair and Surgical Maze: Case Report and Review of the Literature. World Journal of Cardiovascular Diseases, 7, 64-70.

https://doi.org/10.4236/wjcd.2017.73007

Received: December 12, 2016

Accepted: March 5, 2017

Published: March 8, 2017

Copyright () 2017 by authors and Scientific Research Publishing Inc. This work is licensed under the Creative Commons Attribution International License (CC BY 4.0).

http://creativecommons.org/licenses/by/4.0/

\begin{abstract}
Hereby we describe a case of LAF developed after a surgical Maze procedure that demonstrates the importance of a systematic approach to mapping and ablating atypical atrial flutter to prevent a recurrence of symptomatic arrhythmia. In patients with previous cardiac surgery procedures, and in particular after a surgical maze, there are many different potential LA reentry circuits that involve various pathways. Both activation mapping and entrainment mapping were performed in order to identify the critical isthmus of the circuit and to effectively terminate the arrhythmia.
\end{abstract}

\section{Keywords}

Atypical Flutter, Left Atrial Flutter, Mitral Valve Surgery, Surgical Maze

\section{Introduction}

Atypical atrial flutter is a regular arrhythmia characterized by a non-cavotricuspid isthmus dependent macro-reentry. Considering that atypical atrial flutter reentry circuit may involve various locations in both atria, activation mapping of the flutter circuit is important to confirm that catheter ablation is being performed at an isthmus involved in the circuit. Left atrial flutter (LAF) most commonly involves reentry around a scar from prior cardiovascular surgery, catheter ablation, or congenital heart disease. One aspect that derives from the widespread diffusion of ablation procedures for atrial fibrillation, both percutaneous and surgical, is the onset of LAF linked to the presence of a gap at the pulmonary vein $(\mathrm{PV})$ ostia or antra.

\section{Case Report}

A 72-year-old man presented at our Centre for an elective atrial flutter ablation 
procedure. Previous cardiac history includes myxomatous mitral valve, severe prolapse with flail of the mitral posterior leaflet with severe mitral valve regurgitation requiring mitral valve repair at age 69 . He also had history of paroxysmal atrial fibrillation. At the time of his valve surgery, the left atrial appendage was removed and a simplified Cox-MazeIII procedure (PV encircling and connecting lines) was also performed. Three years after surgery, he developed symptomatic rapid atrial flutter. The patient complained for mild swelling of his ankles and worsening shortness of breath on exertion. He received oral anticoagulation therapy and rate control treatment with metoprolol was started waiting for catheter ablation. He was scheduled for atrial flutter ablation after transesophageal echocardiogram. Procedure was performed in fasting state and under conscious sedation. The patient was brought to the electrophysiology lab in atrial flutter. 12-lead ECG showed flutter waves morphology positive in V1, flat in lead I, and negative in lead II, III, Avf (Figure 1). Venous access was obtained twice through the right femoral vein. A 6 Fr decapolar deflectable catheter was advanced into the right atrium and placed into the coronary sinus (CS). The CS activation sequence was distal to proximal, compatible with an atypical LAF and the cycle length was $260 \mathrm{msec}$ (Figure 2). Transseptal access to the left atrium (LA) was then established from the right femoral vein under fluoroscopic guidance using contrast injection to visualize the fossa ovalis and the left atrial cavity. Systemic anticoagulation with heparin was given in order to maintain an activated clotting time $>300$ seconds. A $3.5 \mathrm{~mm}$ tip Thermo Cool Surround Flow bidirectional F-J curve catheter (Biosense Webster Inc., Diamond Bar, CA, USA) was placed into the LA.

The ablation catheter was sequentially moved into the LA to map the PVostia and antra. All the PV antra, the posterior wall and the roof were silent. Interestingly, a dissociated potential was recorded on the posterior wall (Figure 3). We found LA potentials only in the mitral isthmus region. Entrainment of the tachycardia was performed from the mitral isthmus region pacing at $230 \mathrm{msec}$. The difference of the post-pacing interval (PPI) and the tachycardia cycle length (TCL) after the entrainment pacing indicates the proximity of the entrainment catheter to the reentry circuit, and the PPI-TCL at the mitral isthmus was 10 msec with concealed entrainment (Figure 4). This was indicative that the mitral isthmus was part of the critical zone of the reentry circuit. A mitral isthmus line from the left inferior PV to the mitral isthmus was performed. During ablation, the atrial flutter terminated (Figure 5), and the ablation line was completed from the left inferior PV to the mitral valve annulus. After ablation, we demonstrated failure to capture at maximum output (20 V @ $3 \mathrm{~ms}$ ) on the line, and significant conduction delay was recorded while pacing the LA across the line. Repeated atrial stimulations, on and off isoproterenol infusion up to $4 \mathrm{mcg} / \mathrm{min}$, with atrial programmed stimulation and burst down to the atrial refractory period demonstrated no inducible atrial arrhythmia. Post-procedure, the patient recovered well with no complications. His dyspnea on exertion resolved, and he remains in stable sinus rhythm after 9 months of follow-up. 


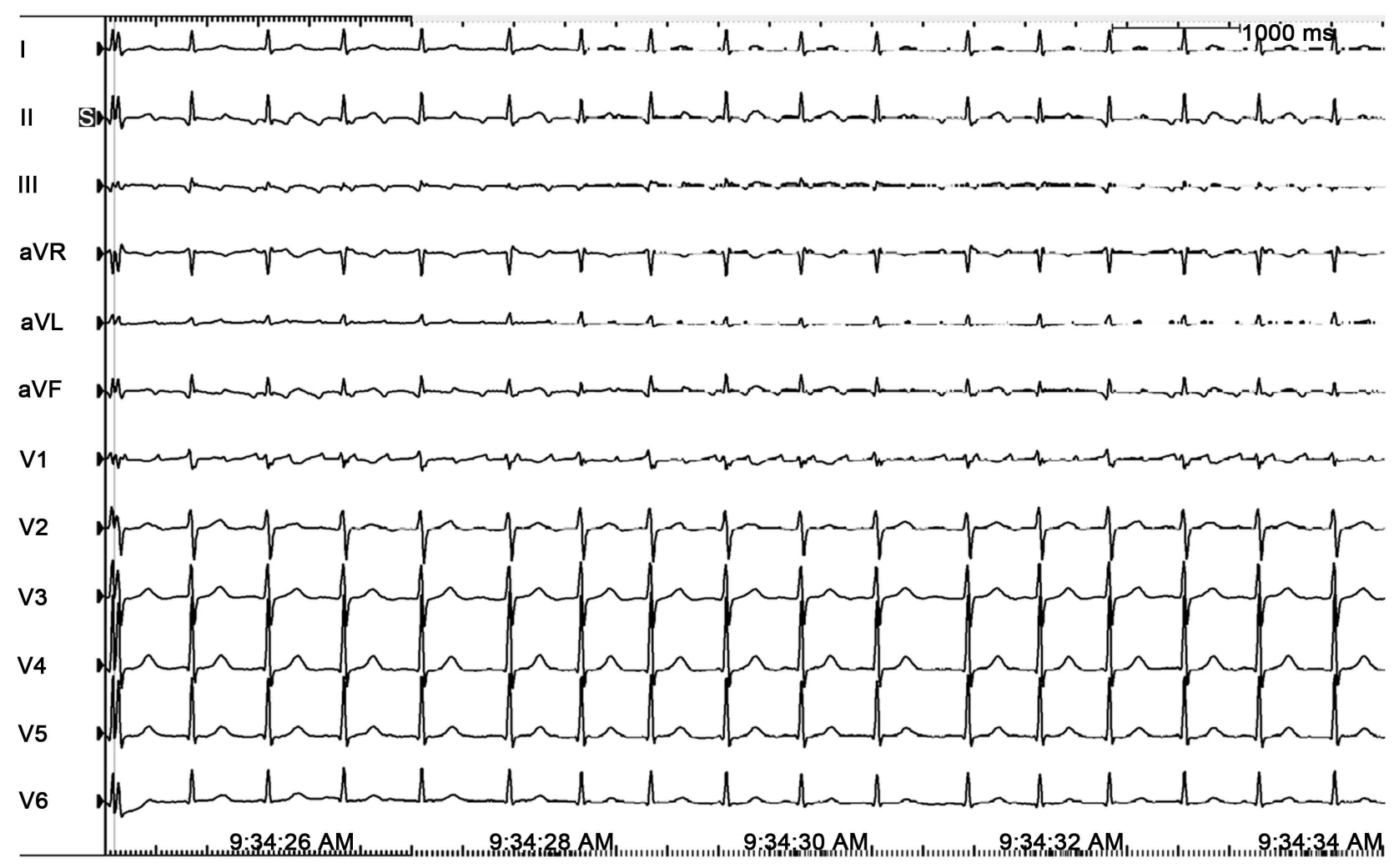

Figure 1. 12-lead ECG shows atrial flutter with flutter waves morphology positive in V1, flat in lead I, and negative in lead II, III, aVF.

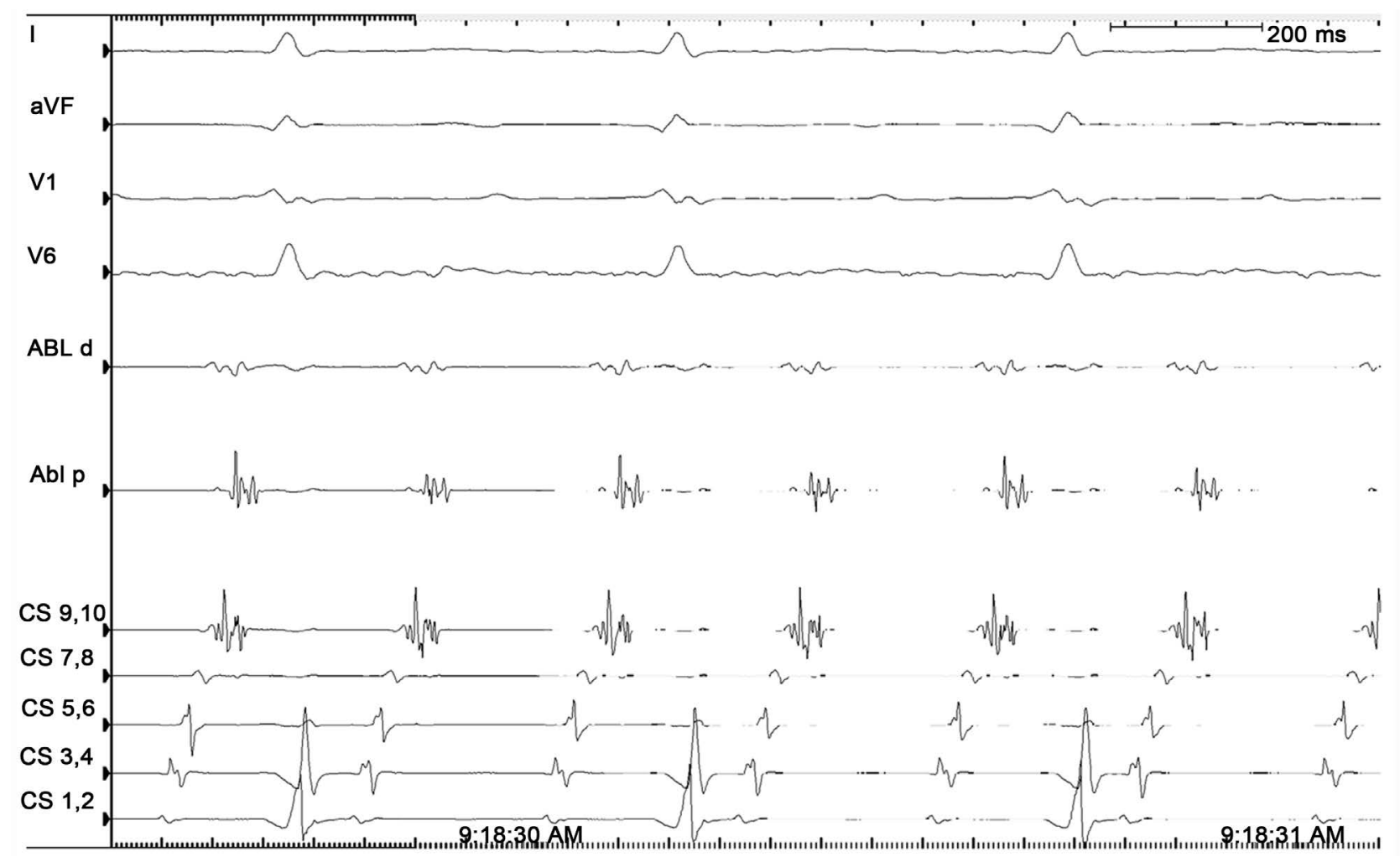

Figure 2. Coronary sinus (CS) activation sequence is distal (CS 1-2) to proximal (CS 9-10), compatible with an atypical LAF. The cycle length of the flutter is $260 \mathrm{msec}$. 


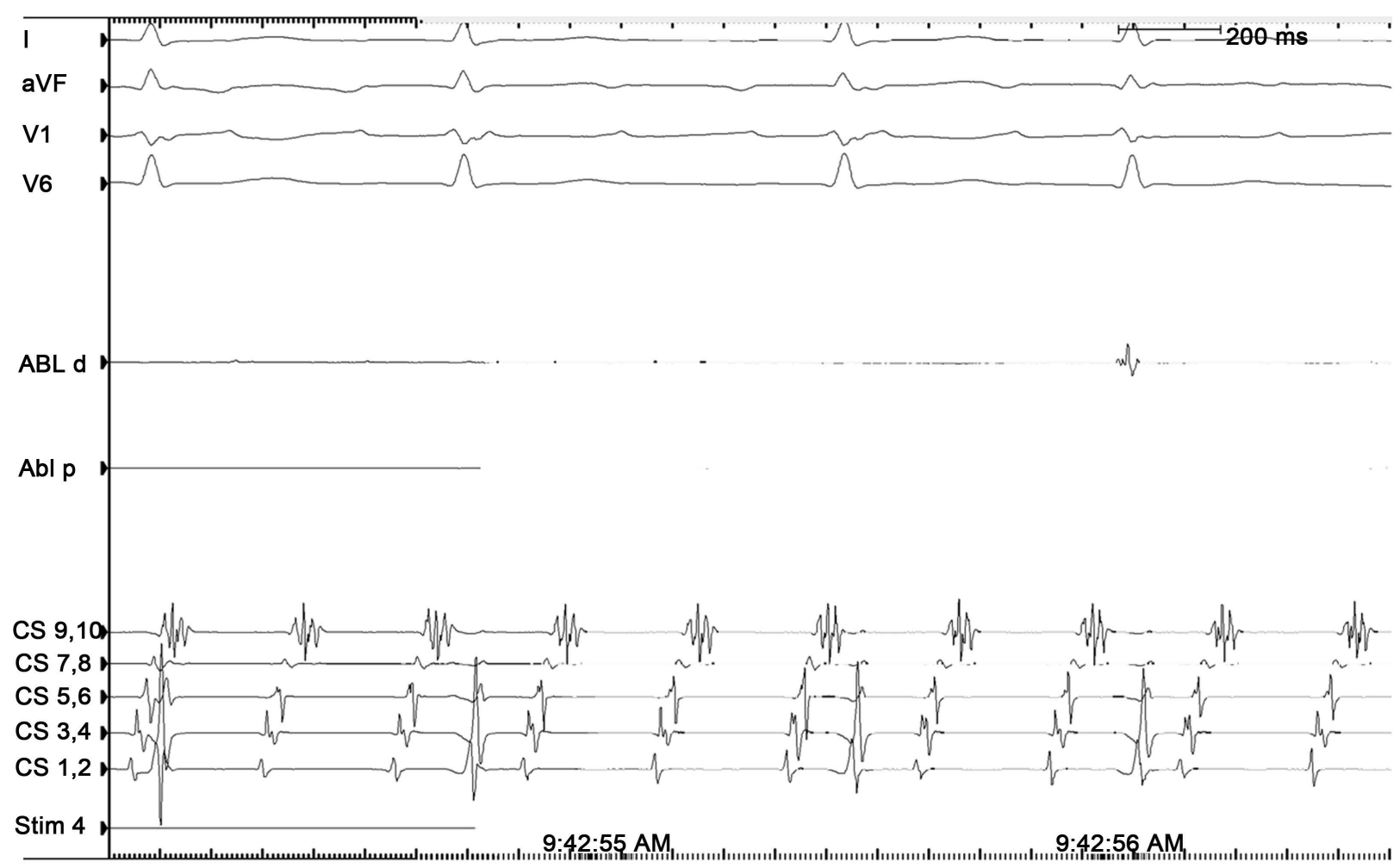

Figure 3. A dissociated potential is recorded from the ablation catheter $(\mathrm{ABL} d)$ on the posterior wall of the left atrium.

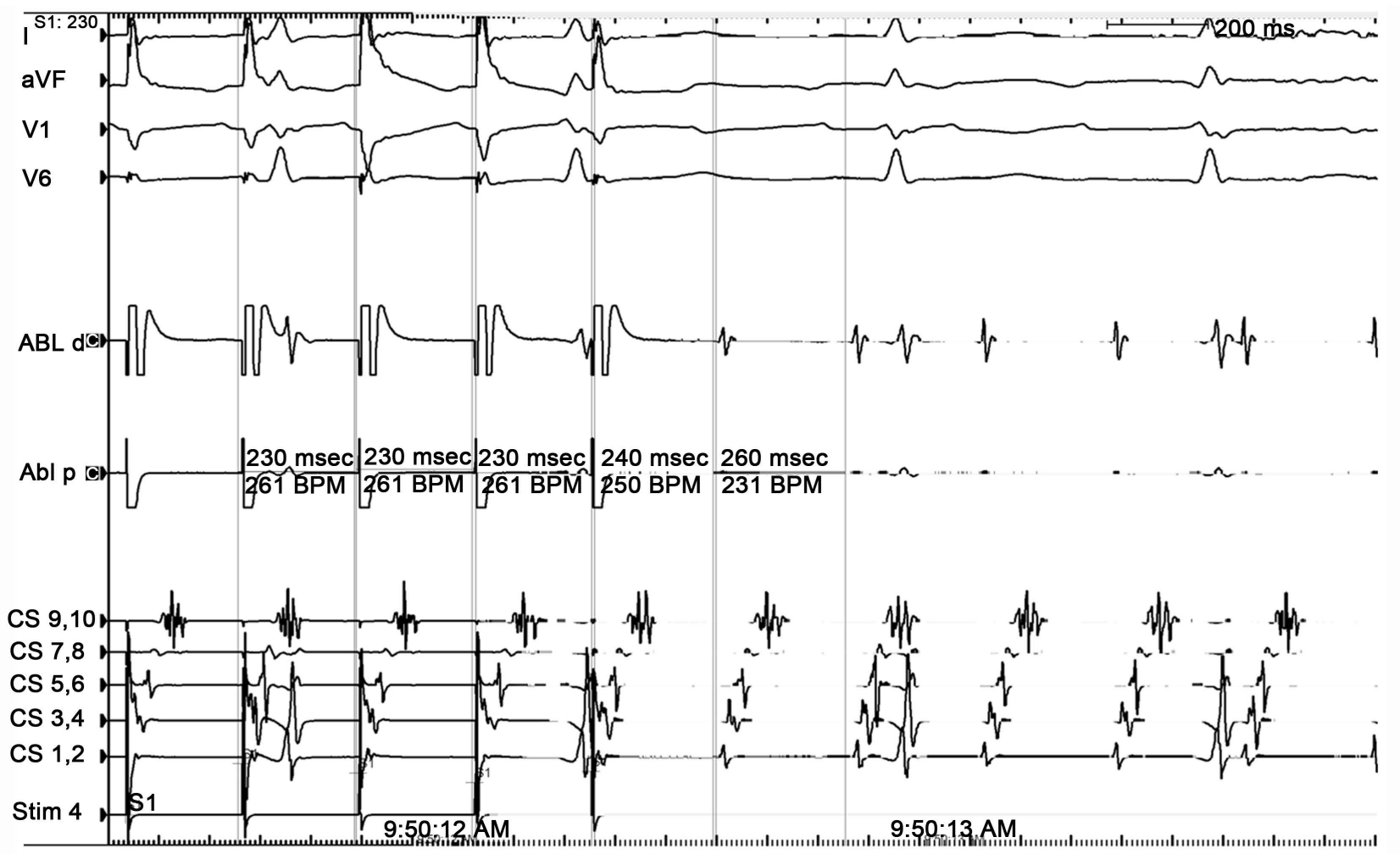

Figure 4. Entrainment of the tachycardia (CL $260 \mathrm{msec}$ ) is performed from the mitral isthmus region pacing at $230 \mathrm{msec}$. The difference of the post-pacing interval (PPI) and the tachycardia cycle length (TCL) after the entrainment pacing indicates the proximity of the entrainment catheter to the reentry circuit, and the PPI-TCL at the mitral isthmus is 10 msec with concealed entrainment. 


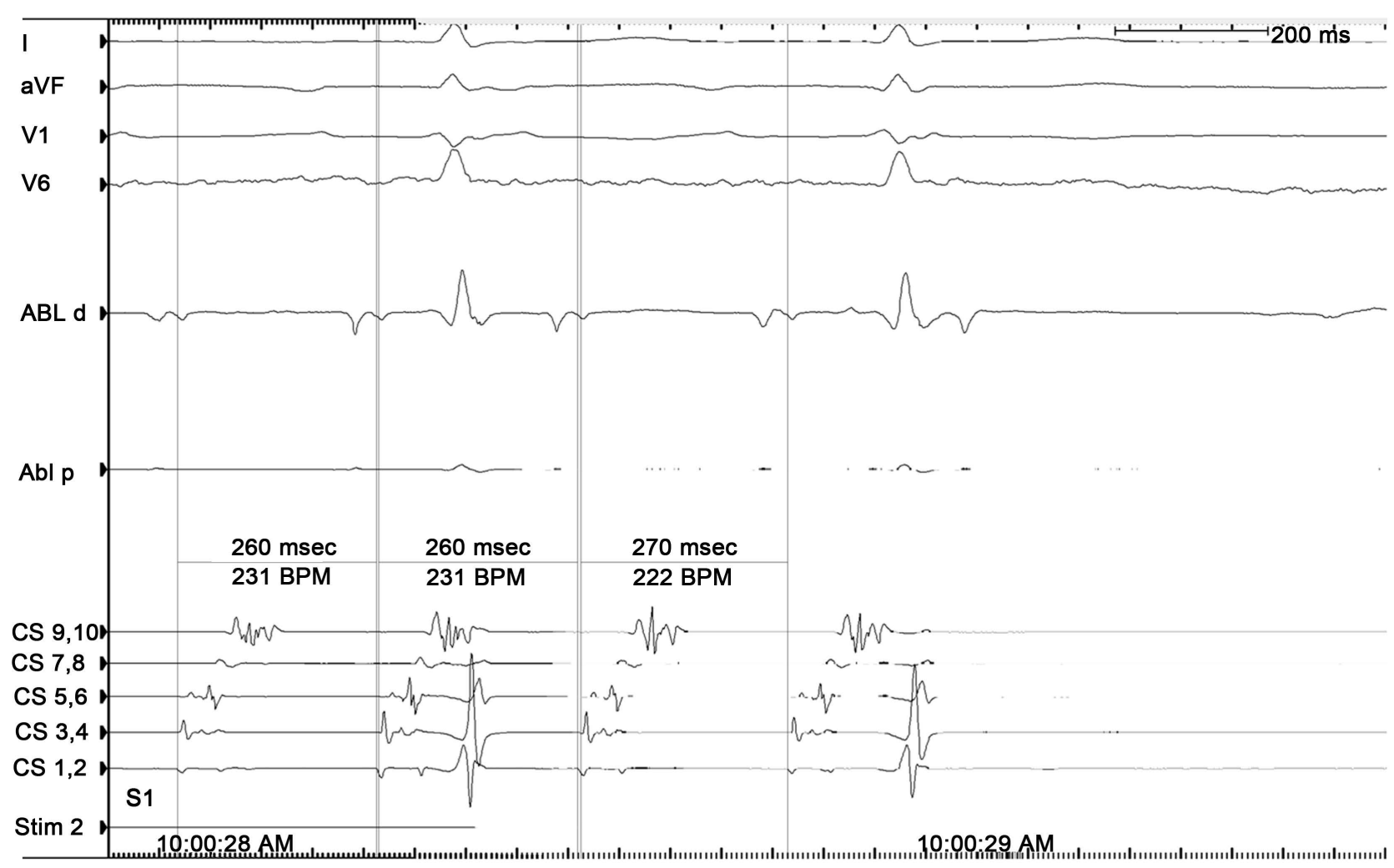

Figure 5. During ablation on the mitral isthmus, the atrial flutter prolonged $(270 \mathrm{msec})$ and then terminated.

\section{Discussion}

Cardiac surgeons were the pioneers of curative ablation of atrial fibrillation (AF). Since the 80's, when Cox and colleagues introduced the LA isolation procedure to restore regular rhythm and containing AF to the LA in dogs, several techniques have been developed. The "cut-and-sew" surgeries performed under direct visualization (Cox-Maze I to III procedures), for AF have a success rate ranging from $75 \%-95 \%$ at preventing recurrent arrhythmia [1] [2] [3] [4] [5]. The atrial incisions of the procedure are designed to block potential macroreentrant pathways and narrow the atrial tissue to block propagation of microreentrant wavelets. Moreover, focal activation from PVs is blocked by the isolation of left atrial posterior wall, including all of the PVs.

The most common arrhythmias following a Cox-Maze III procedure include LAF from reentry around the surgical incisions, AF from PV reconnection, and focal atrial tachycardia. Scar-related atypical LAF are difficult to manage medically and frequently recur after electrical cardioversion [6] [7] [8]. Ishii et al. reported that an atrial arrhythmia of some form occurred in $43 \%$ of patients after the Maze procedure and that most of these arrhythmias were AF [9]. Wazni et al. found in their cohort of 23 patients with atrial arrhythmias after surgical maze that $48 \%$ had atypical atrial flutter, with more patients having LAF than right atrial flutter, implying that the surgery itself creates a substrate that can lead to another arrhythmia. They also found that AF recurrence was secondary to recovery of conduction around the lines encircling the PVs [10]. Bai et al. 
found that in patients with a prior history of cardiac surgery or AF ablation, the open-irrigated-tip catheter was superior to the 8-mm solid-tip catheter for radiofrequency ablation of scar-related atypical LAF. Patients ablated with the open-irrigated-tip catheter had higher acute success rate and more favorable long-term outcome with more patients maintaining sinus rhythm without antiarrhythmic drugs therapy [11]. Recently, Coffey and colleagues published a multicenter retrospective review of 91 patients with atypical atrial flutter. The authors found that patients with a history of a surgical Cox Maze procedure had the highest long-term success rate, at $88 \%$ over $16 \pm 12$ months [12].

In addition to the activation map performed with a non-fluoroscopic 3D mapping system, successful use of entrainment mapping was crucial to identify the isthmus and to effectively terminate the arrhythmia. Indeed, there are many different potential LA reentry circuits that involve various pathways particularly after a surgical maze procedure (i.e. PV, septum, mitral valve annulus). Entrainment maneuver refers to the concept that pacing at a slightly shorter cycle length than a reentrant tachycardia will accelerate the tachycardia without interrupting it. Concealed entrainment accelerates the tachycardia without fusion on the ECG or intracardiac recordings. If concealed entrainment occurs and the PPI is equal to the TCL, the pacing electrode is likely at an isthmus of slow conduction within the reentry circuit. In atypical LAF, confirming that the ablation catheter is within the reentry circuit by demonstrating concealed entrainment and a PPI-TCL of $\leq 20 \mathrm{~ms}$ is important for the success of the procedure [13] [14]. The most significant limitation of entrainment mapping in patients with atypical flutter is the frequent conversion of the clinical arrhythmia into a different circuit and/or morphology or into AF during pacing.

\section{Conclusion}

Atypical atrial flutter is a challenging arrhythmia that can occur in the presence of atrial scar, often related to either previous cardiac surgery or catheter ablation of AF. Catheter-based mapping and ablation of atypical atrial flutter is feasible and effective, although technically challenging. The combination of activation mapping using a non-fluoroscopic 3D mapping system and entrainment mapping is crucial to achieve satisfying acute success and long-term outcomes.

\section{References}

[1] Cox, J.L., Boineau, J.P., Schuessler, R.B., Kater, K.M. and Lappas, D.G. (1993) Five-Year Experience with the Maze Procedure for Atrial Fibrillation. The Annals of Thoracic Surgery, 56, 814-823. https://doi.org/10.1016/0003-4975(93)90338-I

[2] Cox, J.L., Schuessler, R.B., D’Agostino, H.J.J., Stone, C.M., Chang, B.C., Cain, M.E., Corr, P.B. and Boineau, J.P. (1991) The Surgical Treatment of Atrial Fibrillation. III. Development of a Definitive Surgical Procedure. The Journal of Thoracic and Cardiovascular Surgery, 101, 569-583.

[3] McCarthy, P.M., Gillinov, A.M., Castle, L., Chung, M. and Cosgrove, D. (2000) The Cox-Maze Procedure: The Cleveland Clinic Experience. Seminars in Thoracic and Cardiovascular Surgery, 12, 25-29. https://doi.org/10.1016/s1043-0679(00)70013-x 
[4] Prasad, S.M., Maniar, H.S., Camillo, C.J., Schuessler, R.B., Boineau, J.P., Sundt, T.M., Cox, J.L. and Damiano, R.J.J. (2003) The Cox Maze III Procedure for Atrial Fibrillation: Long-Term Efficacy in Patients Undergoing Lone versus Concomitant Procedures. The Journal of Thoracic and Cardiovascular Surgery, 126, 1822-1828. https://doi.org/10.1016/s0022-5223(03)01287-X

[5] Raanani, E., Albage, A., David, T.E., Yau, T.M. and Armstrong, S. (2001) The Efficacy of the Cox/Maze Procedure Combined with Mitral Valve Surgery: A Matched Control Study. European Journal Cardio-Thoracic Surgery, 19, 438-442. https://doi.org/10.1016/S1010-7940(01)00576-0

[6] Oral, H., Knight, B.P. and Morady, F. (2003) Left Atrial Flutter after Segmental Ostial Radio Frequency Catheter Ablation for Pulmonary Vein Isolation. Pacing and Clinical Electrophysiology, 26, 1417-1419.

https://doi.org/10.1046/j.1460-9592.2003.t01-1-00202.x

[7] Gerstenfeld, E.P., Callans, D.J., Dixit, S., Russo, A.M., Nayak, H., Lin, D., Pulliam, W., Siddique, S. and Marchlinski, F.E. (2004) Mechanisms of Organized Left Atrial Tachycardias Occurring after Pulmonary Vein Isolation. Circulation, 110, 1351 1357. https://doi.org/10.1161/01.CIR.0000141369.50476.D3

[8] Chugh, A., Oral, H., Lemola, K., Hall, B., Cheung, P., Good, E., Tamirisa, K., Han, J., Bogun, F., Pelosi, F.J. and Morady, F. (2005) Prevalence, Mechanisms, and Clinical Significance of Macroreentrant Atrial Tachycardia during and Following Left Atrial Ablation for Atrial Fibrillation. Heart Rhythm, 2, 464-471.

https://doi.org/10.1016/j.hrthm.2005.01.027

[9] Ishii, Y., Gleva, M.J., Gamache, M.C., Schuessler, R.B., Boineau, J.P., Bailey, M.S. and Damiano, R.J.J. (2004) Atrial Tachyarrhythmias after the Maze Procedure: Incidence and Prognosis. Circulation, 110, 164-168.

[10] Wazni, O.M., Saliba, W., Fahmy, T., Lakkireddy, D., Thal, S., Kanj, M., Martin, D.O., Burkhardt, J.D., Schweikert, R.A. and Natale, A. (2006) Atrial Arrhythmias after Surgical Maze: Findings during Catheter Ablation. Journal of the American College of Cardiology, 48, 1405-1409. https://doi.org/10.1016/j.jacc.2006.05.061

[11] Bai, R., Fahmy, T.S., Patel, D., Di Biase, L., Riedlbauchova, L., Wazni, O.M., Schweikert, R.A., Burkhardt, J.D., Saliba, W. and Natale, A. (2007) Radiofrequency Ablation of Atypical Atrial Flutter after Cardiac Surgery or Atrial Fibrillation Ablation: A Randomized Comparison of Open-Irrigation-Tip and 8-Mm-Tip Catheters. Heart Rhythm, 4, 1489-1496. https://doi.org/10.1016/j.hrthm.2007.07.027

[12] Coffey, J.O., d'Avila, A., Dukkipati, S., Danik, S.A., Gangireddy, S.R., Koruth, J.S., Miller, M.A., Sager, S.J., Eggert, C.A. and Reddy, V.Y. (2013) Catheter Ablation of Scar-Related Atypical Atrial Flutter. Europace, 15, 414-419. https://doi.org/10.1093/europace/eus312

[13] Waldo, A.L., MacLean, W.A.H., Karp, R.B., Kouchoukos, N.T. and James, T.N. (1997) Entrainment and Interruption of Atrial Flutter with Atrial Pacing: Studies in Man Following Open Heart Surgery. Circulation, 56, 737-745. https://doi.org/10.1161/01.CIR.56.5.737

[14] Waldo, A.L. (1997) Atrial Flutter: Entrainment Characteristics. Journal of Cardiovascular Electrophysiology, 8, 337-352. https://doi.org/10.1111/j.1540-8167.1997.tb00798.x 
Submit or recommend next manuscript to SCIRP and we will provide best service for you:

Accepting pre-submission inquiries through Email, Facebook, LinkedIn, Twitter, etc. A wide selection of journals (inclusive of 9 subjects, more than 200 journals)

Providing 24-hour high-quality service

User-friendly online submission system

Fair and swift peer-review system

Efficient typesetting and proofreading procedure

Display of the result of downloads and visits, as well as the number of cited articles Maximum dissemination of your research work

Submit your manuscript at: http://papersubmission.scirp.org/

Or contact wicd@scirp.org 